\title{
A Study To Assess The Effectiveness Of Group Therapy On Improving Quality Of Life Among The Caregivers Of Mentally Ill Patient At Selected Mental Hospitals Of Vadodara District"
}

\author{
Arpita Patel ${ }^{1}$, Suresh $V^{2}$, Janki Patel ${ }^{3}$ \\ ${ }^{1}$ Student, Sumandeep Nursing College, Sumandeep Vidyapeeth, Piparia, Vadodara-391760, Gujarat, India, \\ ${ }^{2}$ Associate Professor, Department of Mental Health Nursing, Sumandeep Nursing College, Sumandeep \\ Vidyapeeth, Piparia, Vadodara-391760, Gujarat, India \\ ${ }^{3}$ Assistant Professor, Department of Mental Health Nursing, Sumandeep Nursing College, Sumandeep \\ Vidyapeeth, Piparia, Vadodara-391760, Gujarat, India,
}

\begin{abstract}
Their quality of life is poor due to lack of sleep, constant attention on patient and patient's activity so their day to day activity got altered and that's why caregivers of mentally ill patient's quality of life is poor The Aim of my study is the effectiveness of group therapy in improving quality of life among the caregivers of mentally ill patient.Objectives:1. To assess the effectiveness of group therapy on caregivers of mentally ill.2. To evaluate the effectiveness of group therapy for an improvement of quality of life of caregivers.3. To find out the association between pre-test score of the samples with their selected demographic variables. Pre experimental one group pre-test - post-test research design, and non-probability convenience sampling technique was adopted. The tool used for data collection was observation check list. Sample size was 30 caregivers of mentally ill patient in Vadodara district. About $53.3 \%$ of the study subjects were having poor Quality of life followed by $46.7 \%$ were having average Quality of life in pre-test data. And 't' value of pre-test post-test data is 25.33 and mean $42.61 \%$. The 't' value is significant. So it reveals that group therapy is effective and improves the quality of life of caregivers of mentally ill patient.
\end{abstract}

Key words: Effectiveness, group therapy, quality of life, caregivers of mentally ill patient.

\section{Introduction}

"Never give up on someone with a mental illness. When "I" is replaced by "We", illness becomes wellness."

- Shannon L. Alder

There are approximately 450 million people in the world are dealing with mental illness. So many mentally ill patients are living with family and friends for support and for taking help in their daily activities. Caregivers are playing an important role in development in medical and psychiatric care. Caregivers find another way for broad role in health and social service system. Caregivers of patient with neurological disorders need energy, empathy, tireless effort for daily lives. Care giving has physical, social, emotional, and financial impacts. Mental disorders are economically very costly illnesses in the world. Only emotional and physical health of caregivers are not an important for their quality of life but also for the well-being of the person who receiving their care. The risk of hospitalization of a loved one increases with a decline in the caregiver's physical and mental health. ${ }^{1}$

Care givers of mentally ill are high risk for many different physical and mental health challenges. Generally, the caregivers are suffering from high levels of stress and frustration seen higher level of depression than the other general population. Caregivers are physically less healthy than other peoples and also caregivers have more chronic illness like high blood pressure, cardiac disease, endocrinal disease and arthritis than noncaregivers. Caregivers suffer from proper immune function and from exhaustion. Caregivers avoid their selfcare (have poor levels of own care and preventive health than others) and also caregivers have higher mortality rate than non-caregivers of same age. ${ }^{2}$

Caring of mentally ill patient can be challenging, potentially impacting. Caregiver's health, mental health, work, social relationship and quality of life. To alleviate caregiver stress, enable caregivers to better cope with the demands of caring for a loved one, and improve caregiver and care recipient outcomes, many interventions have been developed. However, although programs supporting caregivers have proliferated, there exists limited research regarding their effectiveness. ${ }^{3}$ 


\section{Conceptual Framework}

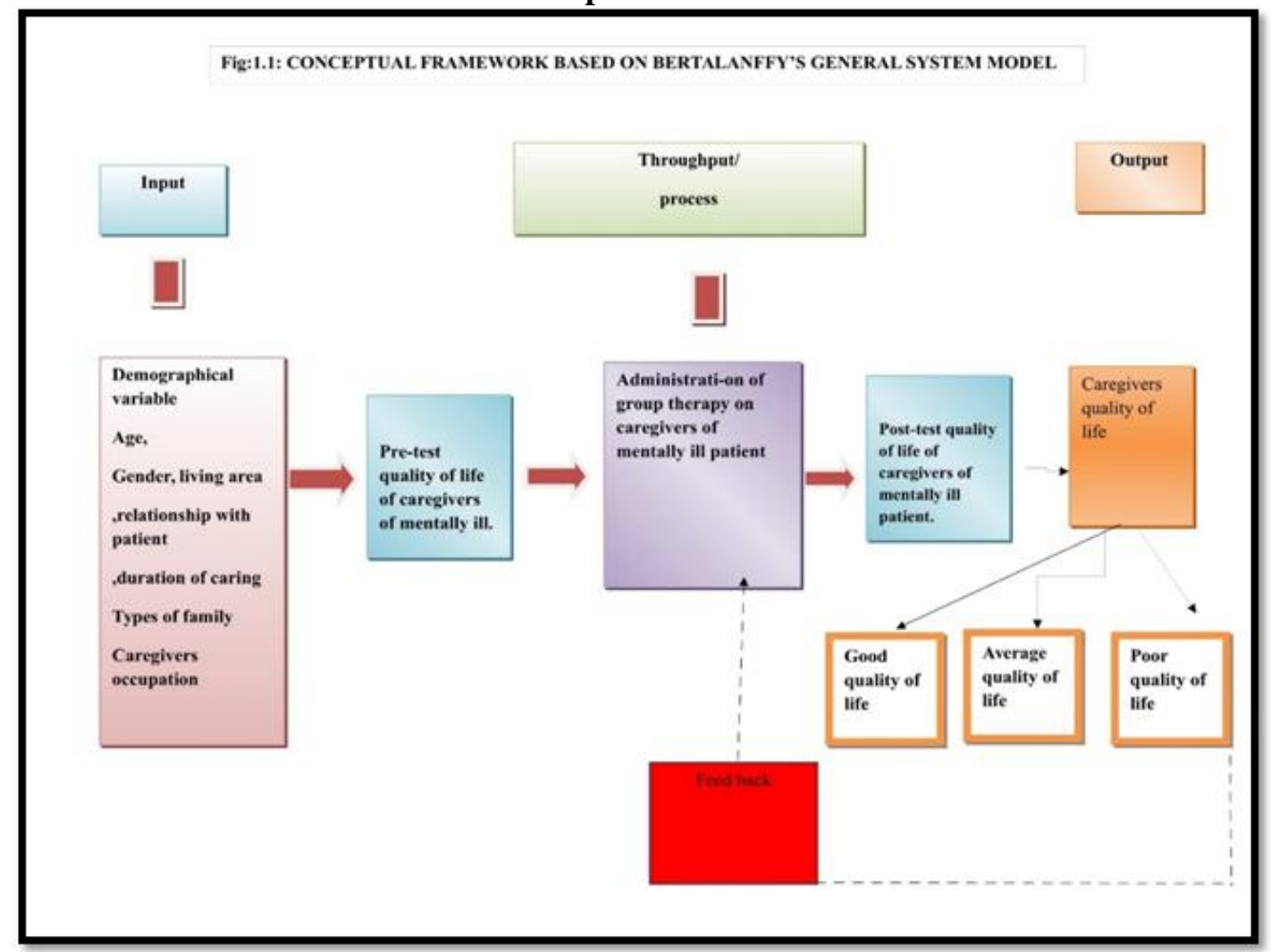

This above conceptual framework is based on general system's theory by von Bertalanffy's (1968). He defines system as a complex interaction between two or more converted elements which form an organized whole and which interact with each other.

\section{Research Methodology}

RESEARCH APPROACH: Quantitative research approach

RESEARCH DESIGN: One group pre-test, post-test pre experimental design.

RESEARCH HYPOTHESIS:

$\mathbf{H}_{1}$ : There will be significant different between pre-test and post-test quality of life among the caregivers of mentally ill patient.

$\mathbf{H}_{2}$ : There will be significant association between pre-test score with their selected socio-demographic variables SETTING OF THE STUDY: Mental hospitals of Vadodara district.

POPULATION: caregivers of mentally ill patient

SAMPLE: 30 caregivers of mentally ill patient

SAMPLING TECHNIQUE: Non probability convenient sampling technique

INSTRUMRNT USED: Quality of life rating scale.

CONTENT VALIDITY: MD Psychiatry, Psychologist and $3 \mathrm{MSc}(\mathrm{N})$ in mental health nursing.

RELIABILITY: Tool was established using the data collected from 3 caregivers of mentally ill patient. Reliability value obtained by using Spearman's brown prophecy formula and got reliability 0.769

\section{Result}

The collected data is tabulated, analysed, and interpreted using descriptive and inferential statistics; the findings are presented under the following headings:

Section A: It consists of demographic variables, which are documented for analysis, frequency and percentage distribution.

Section B: It consists of findings on scores of quality of life in caregivers of mentally ill patient.

Section C: It consists of association between selected demographic variables and caregiver's quality of life. 
SECTION A-Distribution of samples based on demographic data

This action dealt with demographic variables, which are documented for analysis, frequency and percentage distribution.

\begin{tabular}{|c|c|c|c|}
\hline & & & \\
\hline Sr. no. & Variables & Frequency & Percentage \\
\hline \multirow[t]{4}{*}{1.} & \multicolumn{3}{|l|}{ Age(years) } \\
\hline & $20-35$ & 09 & $30 \%$ \\
\hline & $36-50$ & 13 & $43.3 \%$ \\
\hline & Above50 & 08 & $26.7 \%$ \\
\hline \multirow[t]{3}{*}{2.} & \multicolumn{3}{|l|}{ Gender } \\
\hline & Male & 15 & $50 \%$ \\
\hline & Female & 15 & $50 \%$ \\
\hline \multirow[t]{3}{*}{3.} & \multicolumn{3}{|l|}{ Living area } \\
\hline & Rural & 12 & $40 \%$ \\
\hline & Urban & 18 & $60 \%$ \\
\hline \multirow[t]{5}{*}{4.} & \multicolumn{3}{|l|}{ Relationship with patient } \\
\hline & Friend & 03 & $10 \%$ \\
\hline & Family member & 06 & $20 \%$ \\
\hline & Parent & 11 & $36.7 \%$ \\
\hline & Son-daughter & 10 & $33.3 \%$ \\
\hline \multirow[t]{5}{*}{5.} & \multicolumn{3}{|l|}{ Duration of caring } \\
\hline & $0-5$ years & 06 & $20 \%$ \\
\hline & $6-10$ years & 15 & $56 \%$ \\
\hline & $11-15$ years & 07 & $23.3 \%$ \\
\hline & Above 16 years & 02 & $6.7 \%$ \\
\hline \multirow[t]{4}{*}{6.} & \multicolumn{3}{|l|}{ Types of family } \\
\hline & Joint & 15 & $50 \%$ \\
\hline & Nuclear & 14 & $46.7 \%$ \\
\hline & Extended & 01 & $3.3 \%$ \\
\hline \multirow[t]{3}{*}{7.} & \multicolumn{3}{|l|}{ Occupation of caregiver } \\
\hline & Working & 15 & $50 \%$ \\
\hline & Non-working, House wife & 15 & $50 \%$ \\
\hline
\end{tabular}

Section B: It consists of findings on scores of quality of life in caregivers of mentally ill patient.

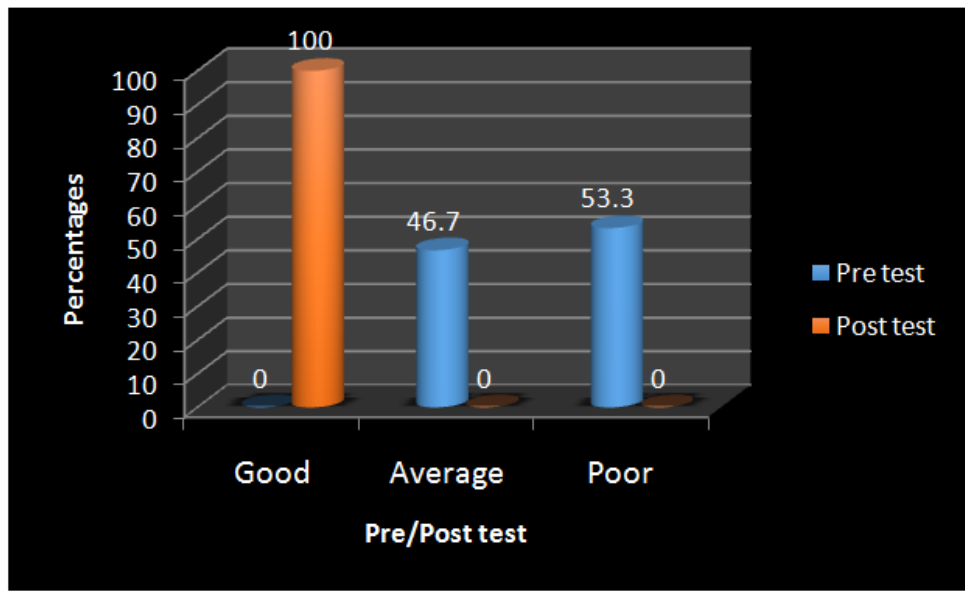

About $53.3 \%$ of the study subjects were having poor Quality of life followed by $46.7 \%$ were having average Quality of life in pre-test data. All the study subjects were having good Quality of life in post test data. Statistically, significant difference was present in Quality of life of pre and post test data.

\begin{tabular}{|c|c|c|c|c|c|c|c|c|c|c|}
\hline & Total & \multicolumn{3}{|c|}{ Pre test } & \multicolumn{3}{|c|}{ Post test } & \multicolumn{2}{|c|}{ Effectiveness } \\
& Score & Mean & SD & $\begin{array}{c}\text { Mean } \\
(\%)\end{array}$ & Mean & SD & $\begin{array}{c}\text { Mean } \\
(\%)\end{array}$ & Mean & SD & $\begin{array}{c}\text { Mean } \\
(\%)\end{array}$ \\
\hline $\begin{array}{c}\text { Quality } \\
\text { of life }\end{array}$ & 120 & $\begin{array}{c}\text { Value } \\
\text { (\% }\end{array}$ & 11.58 & 77.14 & 41.43 & 3.14 & 34.52 & 51.13 & 11.0 \\
6 & 42.61 & 25.33 \\
\hline
\end{tabular}


A Study To Assess The Effectiveness Of Group Therapy On Improving Quality Of Life Among The

Section C: It consists of association between selected demographic variables and caregiver's quality of life.

\begin{tabular}{|c|c|c|c|c|c|c|c|}
\hline \multirow[t]{2}{*}{ sr.no } & \multirow[t]{2}{*}{ variable } & \multicolumn{3}{|c|}{ level of } & \multirow[t]{2}{*}{ total } & \multirow[t]{2}{*}{$x^{2}$} & \multirow[t]{2}{*}{ table value } \\
\hline & & good & average & poor & & & \\
\hline 1 & & \multicolumn{3}{|c|}{ AGE } & & \multirow{5}{*}{2.06} & \\
\hline & $20-35$ & 0 & 5 & 4 & 9 & & \multirow{4}{*}{5.99} \\
\hline & $36-50$ & 0 & 7 & 6 & 13 & & \\
\hline & $>50$ & 0 & 2 & 6 & 8 & & \\
\hline & TOTAL & 0 & 14 & 16 & 30 & & \\
\hline & \multicolumn{5}{|c|}{ GENDER } & & \\
\hline 2 & Male & 0 & 8 & 7 & 15 & \multirow[t]{3}{*}{3.02} & \multirow[t]{3}{*}{3.84} \\
\hline & Female & 0 & 6 & 9 & 15 & & \\
\hline & TOTAL & 0 & 14 & 16 & 30 & & \\
\hline 3 & \multicolumn{4}{|c|}{ LIVING AREA } & & \multirow[t]{5}{*}{3.87} & \multirow[t]{5}{*}{3.84} \\
\hline & Rural & 0 & 3 & 9 & 12 & & \\
\hline & Urban & 0 & 11 & 7 & 18 & & \\
\hline & Total & 0 & 14 & 16 & 30 & & \\
\hline \multirow[t]{6}{*}{4} & \multicolumn{5}{|c|}{ RELATIONSHIP WITH PATIENT } & & \\
\hline & Friend & 0 & 1 & 2 & 3 & \multirow[t]{5}{*}{3.29} & \multirow[t]{5}{*}{7.81} \\
\hline & Family members & 0 & 3 & 3 & 6 & & \\
\hline & Parents & 0 & 5 & 6 & 11 & & \\
\hline & Son-daughter & 0 & 5 & 5 & 10 & & \\
\hline & Total & 0 & 14 & 16 & 30 & & \\
\hline \multirow[t]{6}{*}{5} & \multicolumn{5}{|c|}{ DURATION OF CARING } & & \\
\hline & $0-5$ years & 0 & 4 & \multicolumn{2}{|c|}{6} & \multirow[t]{6}{*}{4.36} & \multirow[t]{6}{*}{7.81} \\
\hline & $6-10$ years & 0 & 5 & 10 & 15 & & \\
\hline & $11-15$ years & 0 & 3 & 4 & 7 & & \\
\hline & More than 16 years & 0 & 2 & 0 & 2 & & \\
\hline & Total & 0 & 14 & 16 & 30 & & \\
\hline \multirow[t]{5}{*}{6} & & & S OF FAM & & & & \\
\hline & Joint & 0 & 9 & 6 & 15 & \multirow[t]{5}{*}{5.62} & \multirow[t]{5}{*}{5.99} \\
\hline & Nuclear & 0 & 5 & 9 & 14 & & \\
\hline & Extended & 0 & 0 & 1 & 1 & & \\
\hline & Total & 0 & 14 & 16 & 30 & & \\
\hline 7 & & CAR & ER'S OCC & & & & \\
\hline & Working & 0 & 7 & 8 & 15 & 0.00 & 7.81 \\
\hline & Non-working & 0 & 7 & 8 & 15 & & \\
\hline & Total & 0 & 14 & 16 & 30 & & \\
\hline
\end{tabular}

*Significant at $5 \%$ Level,

NS=Not significant

Pre-test: - In this study, it highlights that the quality of life score mean percentage is 77.14 with a standard of 11.58 Out of 30 caregivers $0 \%$ have good quality of life, $46.7 \%$ have average quality of life, $53.3 \%$ have poor quality of life.

Post-test: - In this study, it highlights that the quality of life score mean percentage is $42.61 \%$ with a standard deviation of 11.06. Out of 30 caregivers, none of them is having poor and average quality of life and $100 \%$ have good quality of life.

Analysis of paired t test is done to assess the effectiveness of group therapy for improving quality of life. Researcher has found $t$ value $=25.33$ thus the obtained $t$ value in this study is more than the table value of $t$ test at 0.05 level of significance. Hence the obtained t value is significant. So it reveals that caregiver's quality of life is improving after providing group therapy. The association between pre quality of life score and selected socio demographic variables was done with Chi square formula. The obtained $\mathrm{X}^{2}$ value in some variables such as living area, types of family, caregiver's occupation are more than the table value of $\mathrm{X}^{2}$ at 0.05 level of significance.

\section{Discussion}

The present study was conducted to determine the effectiveness of group therapy on improving quality of life among the caregivers of mentally ill patient at selected mental hospitals of Vadodara district. In order to achieve the objectives of the study, a pre experimental one group pre-test, post-test design was adopted. Non probability convenience sampling technique was used to select the sample. The data was collected from 30 caregivers of mentally ill patient. Before and after administering group therapy with use of observation check list. The findings of the study have been discussed with reference to the objectives, hypothesis, and with the findings of other studies. 


\section{Conclusion}

Review of literature enabled the investigator to develop the conceptual frame work, methodology, setting of the study and plan for data analysis. The conceptual frame work adopted by this study was based on general system model. The research approach adopted in the present study is quantitative and evaluative approach, pre-experimental one group pre-test post-test design was adopted for this study. Non probability convenience sampling technique was used to select the sample and the sample size was 30 caregivers of mentally ill patient.

\section{Acknowledgement}

I Ms. Arpita Patel owe a deep sense of gratitude to whoever contributed to the accomplishment of this study.

\section{References}

[1]. Constaneda D,Sommer R.Mental health professionals attitude toward the family's role in care of the mentally ill. Psychiatric services 1989:40:1195-7

[2]. Dwyer J,Lee G,Jankowski T.Reciprocity,Elder Satisfaction \& caregiver stress and Burden: the exchange of Aid in the family caregiving relationship. J Marriage Fam.1994;56:35-43.

[3]. World health organization report of WHOQOL Focus Group Work:WHO(MHN/PSF/934)1993.

[4]. Advances in Psychiatric Treatment (2003), volume. 9. http://apt.rcpsych.org/

[5]. Merry c. townsend, concepts of care in evidence based practice, $8^{\text {th }}$ edition, page no; 175,176

[6]. Budman,S. H., Demby, A.,Redonao.J.P.,et al(1998)comparative outcome in time-limited individual and group psychotherapy. International journal of group psychotherapy,48,38-63.

[7]. Foulkes, S.H.(1948)introduction to group analytic psychotherapy-the psychoanalytic approach.london:Karnac. 